\title{
TRATAMENTOS PRÉ-GERMINATIVOS E PROCEDÊNCIA DE SEMENTES DO TUCUMÃ-DO-AMAZONAS PARA A PRODUÇÃO DE MUDAS ${ }^{1}$
}

\author{
SANTIAGO LINORIO FERREYRA RAMOS ${ }^{2}$, JEFERSON LUIS VASCONCELOS DE MACÊDO ${ }^{3}$, \\ CIBELE CHALITA MARTINS ${ }^{4}$, RICARDO LOPES ${ }^{5}$, MARIA TERESA GOMES LOPES
}

RESUMO - A germinação rápida e uniforme das sementes, seguida por pronta emergência das plântulas são características altamente desejáveis na formação de mudas. O objetivo deste trabalho foi avaliar o efeito da procedência das sementes, da frequência de troca de água para a hidratação e de choques de temperatura sobre a germinação e a produção de plântulas de tucumã-do-amazonas (Astrocaryum aculeatum). Os frutos foram obtidos em três locais do Estado do Amazonas: Mercado de Manaus e região de Maués e do TarumãAçu. Após limpeza e secagem dos pirênios e extração das sementes, essas foram submetidas à embebição por 15 dias com troca de água: uma e duas vezes ao dia. Após a embebição, foram aplicados os seguintes tratamentos: testemunha sem imersão em $\mathrm{H}_{2} \mathrm{O}$; imersão em $\mathrm{H}_{2} \mathrm{O}$ a 50 e $10^{\circ} \mathrm{C}$ por 5 minutos; imersão em $\mathrm{H}_{2} \mathrm{O}$ a $50^{\circ} \mathrm{C}$ por 5 minutos, seguida por $10^{\circ} \mathrm{C}$ por mais 5 minutos; imersão em $\mathrm{H}_{2} \mathrm{O}$ a $10^{\circ} \mathrm{C}$ por 5 minutos, seguida por $50^{\circ} \mathrm{C}$ por mais 5 minutos. Os tratamentos foram avaliados por meio de pré-germinação, emergência de plântulas no viveiro e produção de mudas. O experimento foi conduzido no delineamento inteiramente ao acaso, com os tratamentos distribuídos em arranjo fatorial $3 \times 2 \times 5$ (locais de procedência x frequências de troca de água $x$ tratamentos de temperatura), em quatro repetições e cinco sementes por parcela. A frequência de troca de água de embebição da semente e a exposição a choques de temperaturas não tem efeito sobre o desempenho germinativo. A procedência de sementes de tucumã-do-amazonas tem efeito na germinação e na produção de mudas.

Termos para indexação: Astrocaryum aculeatum, germinação, embebição.

\section{PRE-GERMINATION TREATMENTS AND ORIGIN OF TUCUMÃ-DO-AMAZONAS SEEDS IN THE PRODUCTION OF SEEDLINGS}

\begin{abstract}
Rapid, uniform seed germination followed by prompt seedling emergence are highly desirable characteristics in seedling production. The aim of this study was to evaluate the effect of seed origin, frequency with which hydration water was changed and thermal shocks on germination and production of tucumã-do-amazonas (Astrocaryum aculeatum) seedlings. Fruits were obtained from three locations in the state of Amazonas: Manaus market, and in Maués and Tarumã-açú. After cleaning and drying the endocarps and removing them, the seeds were soaked for 15 days, changing the water once or twice a day. After soaking, the following treatments were applied: control without immersion in $\mathrm{H}_{2} \mathrm{O}$, immersion for 5 minutes in $\mathrm{H}_{2} \mathrm{O}$ at $50^{\circ} \mathrm{C}$ or $10^{\circ} \mathrm{C}$; immersion for 5 minutes in $\mathrm{H}_{2} \mathrm{O}$ at $50^{\circ} \mathrm{C}$, followed by a further 5 minutes at $10^{\circ} \mathrm{C}$; immersion for 5 minutes in $\mathrm{H}_{2} \mathrm{O}$ at $10^{\circ} \mathrm{C}$, followed by a further 5 minutes at $50^{\circ} \mathrm{C}$. Treatments were evaluated by pre-germination, seedling emergence in the nursery and seedling production. The experiment was conducted in totally randomized design with treatments arranged in a factorial $3 \times 2 \times 5$ (places of origin $\times$ water exchange frequency $x$ temperature treatments) in four replications of five seeds per plot. Germination performance was not affected by the water exchange frequency, nor by exposure to thermal shocks. The origin of tucumã-do-amazonas has effect over the germination and seedling production.
\end{abstract}

Index terms: Astrocaryum aculeatum, germination, soaking.

\footnotetext{
1(Trabalho 217-10). Recibo em:25-10-2010. Aceito para publicação em: 18-07-2011.

${ }^{2}$ Eng. Agr., M.Sc., Bolsista CNPq. Faculdade de Ciências Agrárias; Universidade Federal do Amazonas - UFAM; Av. Gen. Rodrigo Octávio Jordão Ramos, 3000; Campus Universitário, 69077-000. Manaus, Amazonas, Brasil. E-mail: slfr03@hotmail.com

${ }^{3}$ Pesquisador Doutor da Embrapa Amazônia Ocidental; Rodovia AM-10, Km 29, Caixa Postal 319, 69010-970. Manaus, Amazonas, Brasil. E-mail: Jeferson.macedo@cpaa.embrapa.br

${ }^{4}$ Prof. Doutor do Centro Estadual de Educação Tecnológica do Estado de São Paulo "Paula Souza". Faculdade de Tecnologia em Silvicultura- FATEC, Rua Amantino de Oliveira Ramos, nº 60, 18300-000. Capão Bonito-SP, Brazil. E-mail: cibele@fca.unesp.br ${ }_{5}^{5}$ Pesquisador Doutor da Embrapa Amazônia Ocidental; Rodovia AM-10, Km 29, Caixa Postal 319, 69010-970. Manaus, Amazonas, Brasil. E-mail: ricardo.lopes@cpaa.embrapa.br

${ }^{6}$ Prof. Doutor da Faculdade de Ciências Agrárias; Universidade Federal do Amazonas - UFAM; Av. Gen. Rodrigo Octávio Jordão Ramos, 3000; Campus Universitário, B1. V, Sala 1; 69077-000. Manaus, Amazonas, Brasil.. E-mail: mtglopes@ufam.edu.br
} 


\section{INTRODUÇÃO}

O tucumã-do-amazonas (Astrocaryum aculeatum G. Mey.) é uma palmeira tropical de ocorrência predominante na Amazônia ocidental e central brasileira, em áreas de terra firme (MIRANDA et al., 2001). A população amazônica consome a polpa na forma fresca e, a partir da década de 90 , estabelecimentos comerciais de Manaus passaram a comercializar doces, sorvetes, sanduíches e tapioca com tucumã-do-amazonas (COSTA et al., 2005). Assim, as formas de utilização da polpa na alimentação tem-se diversificado, aumentando a demanda pelo fruto, que é obtido de modo extrativista. A excelente remuneração tem despertado o interesse dos produtores pelo cultivo da planta em escala comercial (FAO, 1987).

O tucumã é propagado por sementes, de forma que tratamentos pré-germinativos que possibilitem uma germinação rápida e uniforme, seguida por pronta emergência das plântulas são importantes na formação de mudas de palmeiras frutíferas, pois quanto mais tempo a plântula permanecer nos estádios iniciais de desenvolvimento, mais vulnerável estará às condições adversas do meio (MARTINS et al., 2009a).

Para favorecer a germinação, as sementes de tucumã devem ser extraídas dos frutos mediante os seguintes procedimentos: retirada do exocarpo e mesocarpo com faca, imersão em água para o amolecimento de resíduos do mesocarpo carnoso, fricção dos pirênios com água e areia para completar a limpeza, secagem para que as sementes se soltem do endocarpo, impacto mecânico para a quebra do endocarpo e extração das sementes. A retirada do endocarpo do tucumã possibilita a redução do tempo de germinação de dois anos para 141 dias (GENTIL; FERREIRA, 2005; FERREIRA; GENTIL, 2006). Após esse processo, estudos demonstraram um efeito benéfico da reidratação das sementes de tucumã sobre a velocidade e uniformidade da germinação, antecipando o início da germinação entre 16 e 18 dias (GENTIL; FERREIRA, 2005; FERREIRA; GENTIL, 2006; NAZÁRIO; FERREIRA, 2010).

O tucumã-do-amazonas é uma espécie pioneira em áreas antrópicas, tendo capacidade de suportar temperaturas elevadas do solo resultantes das queimadas ou alteração do microclima resultante do desmatamento. A mudança brusca de temperatura devido a queimadas ou artificialmente, provocadas pelo choque térmico em laboratório (imersão em água fria seguida de água quente), pode causar trincas e fissuras nas estruturas de recobrimento das sementes devido à rápida distenção, que passam a permitir a livre entrada de água e gases, e a minimizar possíveis impedimentos físicos ao desenvolvimento do eixo embrionário (BRASIL, 2009).

A imersão em água das sementes de $A$. $a c u$ leatum por períodos de 2 a 15 dias, nas temperaturas de 25 a $40^{\circ} \mathrm{C}$, foi favorável à emergência de plântulas, de modo independente das temperaturas e períodos utilizados (FERREIRA; GENTIL, 2006; NAZÁRIO; FERREIRA, 2010). No entanto, outras condições de embebição ou choques térmicos podem favorecer a germinação, desde que seja atingido o grau de umidade de $30 \%$ nas sementes com máximo desempenho germinativo (FERREIRA; GENTIL, 2006; NAZÁRIO; FERREIRA, 2010). Em seu trabalho, Nazário e Ferreira (2010) comentam sobre a necessidade da combinação da embebição com outros tratamentos pré-germinativos para promover a germinação das sementes do tucumã-do-amazonas. Costuma-se adotar a troca diária da água de embebição como um dos tratamentos para facilitar a germinação (FERREIRA; GENTIL, 2006; NAZÁRIO; FERREIRA, 2010).O aumento da frequência de troca de água pode aumentar a taxa de oxigênio, favorecendo o processo de germinação.

No processo de imersão, a troca da água é fundamental para evitar o desenvolvimento de microrganismos e o apodrecimento das sementes, pois promove a oxigenação do meio, cuja troca deve ser realizada diariamente (FERREIRA; GENTIL, 2006; NAZÁRIO; FERREIRA, 2010); mas não foram encontradas informações sobre a frequência da troca de água e consequências sobre a qualidade fisiológica de sementes de tucumã-do-amazonas. Adicionalmente, a intensidade da resposta germinativa das sementes aos tratamentos impostos pode ser influenciada pelo genótipo e procedência da população (MARTINS et al., 2009b). A germinação das sementes de tucumã foi desuniforme, e Gentil e Ferreira (2005) atribuíram, em parte, esta variação à origem do lote de sementes, formado a partir de mistura de progênies. Não existem sementes de qualidade genética para atender à demanda do setor de produção de mudas de tucumã-do-amazonas para uso na agricultura. As sementes, em geral, são adquiridas no mercado de comercialização de frutos, em plantas de populações espontâneas e muitas vezes são recolhidas do chão.

Este trabalho teve como objetivo avaliar o efeito da procedência das sementes, da frequência de troca de água para a hidratação e de choques de temperatura sobre a germinação e produção de plântulas de tucumã-do-amazonas. 


\section{MATERIAL E MÉTODOS}

Os frutos utilizados no trabalho foram obtidos em três locais do Estado do Amazonas: Mercado de Manaus e populações de Maués e do Tarumã-Açu. As sementes das procedências de Maués e de TarumãAçu foram obtidas da mistura de frutos maduros de cinco plantas da população de cada local. Os cachos foram colhidos simultaneamente quando se observou a queda dos primeiros frutos maduros de cada cacho. Para a composição do lote de sementes de cada procedência, no momento da colheita, utilizaram-se os sessenta frutos de cada cacho em fase mais avançada de maturação, visando a diminuir as diferenças de maturação entre frutos do mesmo cacho. A população de Maués é originada do plantio de sementes de frutos selecionados para sabor, e a de Tarumã-Açu é uma população espontânea. Os frutos de cada procedência foram encaminhados ao Laboratório de Dendê e Agroenergia da Embrapa Amazônia Ocidental, Manaus (AM), onde se procedeu à retirada do exocarpo e mesocarpo de cada lote de sementes (GENTIL; FERREIRA, 2005; FERREIRA; GENTIL, 2006).

Os frutos despolpados foram colocados para secar à sombra num galpão com umidade relativa média do ar de $55 \pm 10 \%$ e temperatura média de $25 \pm 3^{\circ} \mathrm{C}$ (determinados por termoigrógrafo), para o desprendimento da semente do endocarpo e, semanalmente, foi determinada a perda da massa úmida dos pirênios até o período total de 35 dias e elaborada uma curva de secagem (GENTIL; FERREIRA, 2005; FERREIRA; GENTIL, 2006). Antes e após a secagem, foi determinado o teor de água das sementes com duas subamostras de cinco unidades, pelo método da estufa a $105^{\circ} \mathrm{C}$ por $24 \mathrm{~h}$ (BRASIL, 2009). Os pirênios foram quebrados para a extração das sementes com auxílio de uma prensa de bancada do tipo morsa, sendo que aquelas danificadas foram eliminadas.

As sementes foram acondicionadas em sacos de polietileno perfurado e imersas em tanques com água por 15 dias. As sementes permaneceram em embebição até atingirem peso constante, procedendo-se à pesagem diária de três subamostras de 10 sementes por procedência para a elaboração de uma curva de embebição.

No processo de embebição, foram avaliadas duas frequências de troca de água: diária e duas vezes ao dia. Após a embebição, as sementes foram amostradas para compor o tratamento-testemunha (1) e as outras remanescentes foram submetidas aos seguintes tratamentos: imersão por 5 minutos $\mathrm{em}_{2} \mathrm{O}$ a $50^{\circ} \mathrm{C}(2)$ e a $10^{\circ} \mathrm{C} \mathrm{(3);} \mathrm{imersão} \mathrm{por} 5$ minutos em $\mathrm{H}_{2} \mathrm{O}$ a $50^{\circ} \mathrm{C}$, seguida por $10^{\circ} \mathrm{C}$ por mais 5 minutos
(4); imersão por 5 minutos em $\mathrm{H}_{2} \mathrm{O}$ a $10^{\circ} \mathrm{C}$, seguida por $50^{\circ} \mathrm{C}$ por mais 5 minutos $(5)$. Os tratamentos foram avaliados por meio das seguintes determinações: pré-germinação - conduzida com quatro subamostras de 20 sementes acondicionadas em saco de polietileno fechado transparente e cheio de ar, sobre a bancada do laboratório, em condições de luz indireta e temperatura de $27 \pm 3^{\circ} \mathrm{C}$; as plântulas que emitiram o botão germinativo foram contabilizadas semanalmente e transferidas para substrato, do sétimo ao $56^{\circ}$ dia após a semeadura. Foram calculadas as porcentagens de sementes pré-germinadas semanalmente. Emergência de plântulas no viveiro e produção de mudas - as sementes pré-germinadas foram transferidas para tubetes com $5 \mathrm{~cm}$ de diâmetro e $13 \mathrm{~cm}$ de comprimento, contendo substrato comercial para produção de mudas (Plantmax), com irrigação diária, e ao final de 343 dias foi calculada a taxa de emergência das plântulas e a formação de mudas em relação à população total de sementes utilizadas para cada tratamento na pré-germinação.

O experimento foi conduzido no delineamento inteiramente ao acaso, com os tratamentos distribuídos em arranjo fatorial $3 \times 2 \times 5$ (locais de procedência $x$ frequências de troca de água $x$ tratamentos de temperatura), em quatro repetições e cinco sementes por parcela. Antes das análises, os dados de pré-germinação foram transformados em $(\mathrm{x}+1)^{1 / 2}$ para a normalização da sua distribuição. Para os dados de secagem, sementes desprendidas dos frutos, embebição das sementes e pré-germinação de sementes devido à natureza quantitativa dos tratamentos que foram avaliados durante um período de tempo, foi feita análise de regressão, as curvas traçadas com equação de segundo grau e escolhidas as significativas com maior coeficiente de determinação $\left(\mathrm{R}^{2}\right)$.

\section{RESULTADOS E DISCUSSÃO}

O desprendimento das sementes de dentro do endocarpo iniciou-se a partir do sétimo dia do início da secagem dos frutos e ocorreu de modo progressivo e similar ao longo do tempo para as três procedências (Figura 1). O período de secagem necessário para o desprendimento de todas as sementes para as três procedências foi de 32 dias. Ao final do período de secagem, ao serem submetidas ao processo de extração, as sementes não estavam visualmente danificadas. Assim, não foram constatadas perdas das sementes por quebramento durante o processo de extração, de modo diferente do relatado por Ferreira e Gentil (2006).

Os teores de água iniciais das sementes das 
procedências Tarumã-Açu, Mercado e Maués foram de $23,6 \%, 21,8 \%$ e $21,0 \%$, respectivamente, e os teores de água dos frutos decresceram com o tempo de secagem até atingirem $16,4 \%, 14,6 \%$ e $13,8 \%$, respectivamente, aos 28 dias (Figura 2). A partir deste período, verificou-se a estabilização da curva de secagem para as três procedências, pois aos 35 dias para os frutos das procedências Tarumã-Açu, Mercado e Maués, constataram-se reduções de, no máximo, $0,0,1$ e 0,2 pontos percentuais, respectivamente, em relação ao período anterior. Em comparação com estes resultados, as sementes de tucumãdo-amazonas utilizadas no trabalho realizado por Ferreira e Nazário (2010) estavam com maiores teores de água inicial (28,9\%) e final (17,6\%), após 30 dias de secagem. Talvez estas diferenças possam ser atribuídas a diferenças no grau de maturação das sementes por ocasião da colheita, do tamanho do pireno/semente ou da espessura do endocarpo. Não obstante, o menor teor de água ao final da secagem (Figura 1) pode ter favorecido maior descolamento das sementes dentro dos frutos, de forma que não houve perdas por quebramento durante o processo de extração.

Após a extração, os teores de água iniciais das sementes das três procedências foram similares, de $14,5 \pm 0,2 \%$, sendo que a absorção de água pelas mesmas ocorreu de modo crescente até o período de aproximadamente 13 dias, quando ocorreu a estabilização da embebição. Pelo formato das curvas, pode-se observar que a velocidade de absorção de água das sementes do Mercado foi maior que a verificada para aquelas das demais procedências. Assim, ao final do período de embebição, o teor de água das sementes da procedência Mercado foi $38 \%$, enquanto das outras foi de 32\% (Figura 3).

Foi verificado significância para o efeito de procedência das sementes e não foi observada interação entre procedências e os tratamentos pré-germinativos avaliados, frequência de troca de água e/ou exposição a choques de temperatura $(\mathrm{P}<0,01)$. Desta forma, pelos dados da Figura 4, verificou-se maior velocidade de germinação e máxima porcentagem de sementes pré-germinadas em Maués, em relação àquelas de Tarumã-Açu, com a porcentagem máxima de pré-germinação $(84 \%)$ aos 21 dias. O menor vigor foi obtido com as sementes da procedência Tarumã-Açu, uma vez que necessitaram de mais do que o dobro deste tempo (49 dias) para atingir um valor máximo de pré-germinação de $68 \%$. As sementes da procedência Mercado não germinaram, pois provavelmente estavam mortas.

O lote da procedência Mercado pode ter sido composto por sementes colhidas antes da maturidade fisiológica, pois os frutos possuíam a finalidade de suprir a comercialização da fruta in natura. Embora exista relato de que os cachos de tucumã-do-amazonas são colhidos quando alguns frutos maduros caem do cacho (FAO, 1987), é preciso realizar trabalhos para verificar se atualmente é prática comum a colheita de cachos sem maturidade fisiológica dos frutos para resistir ao transporte a longas distâncias e prolongar o período pós-colheita. O procedimento de produção de mudas de tucumã-do-amazonas de sementes oriundas dos mercados locais oferece riscos de insucesso, embora Gentil e Ferreira (2005) e Ferreira e Gentil (2006) tenham alcançado resultados com os lotes analisados.

$\mathrm{O}$ adiantado estado de deterioração das sementes do Mercado explica a maior velocidade de embebição (Figura 3), pois as membranas celulares das sementes são as últimas a se organizarem durante o processo de maturação e, quanto mais deterioradas estiverem, menor é a capacidade de regular o fluxo de água entre o meio e a semente, ou seja, embebem mais rapidamente (MARCOS FILHO, 2005). De modo similar, em sementes de açaí com menor velocidade e porcentagem de germinação, as membranas celulares também estavam mais deterioradas (MARTINS et al., 2009b).

A desidratação devido à secagem não foi um fator limitante para a germinação das sementes de tucumã-do-amazonas, pois mesmo após a secagem até níveis relativamente baixos de umidade $(14,5 \pm 0,2 \%)$, a capacidade germinativa manteve-se relativamente alta, entre $68 \%$ e $84 \%$. Informações similares foram relatadas por Ferreira e Gentil (2006).

O intervalo de tempo necessário para todo o procedimento de obtenção de semente pré-germinadas de tucumã-do-amazonas, que envolveu a secagem natural, a reidratação e a germinação completa de sementes de tucumã, variou entre 67 a 95 dias (Figuras $1 ; 2 ; 3$ e 4 ).

Pelos resultados, constatou-se que a procedência das sementes exerceu grande influência na velocidade e na uniformidade da germinação das sementes do tucumã-do-amazonas. Ressalta-se que a população que deu origem à procedência TarumãAçu é uma população espontânea, cuja germinação se beneficiou apenas da seleção natural, enquanto a população de Maués é originada do plantio de várias sementes de bons frutos para sabor em covas, seguido de desbaste quando necessário. Em espécies em domesticação, a resposta da seleção inconsciente e consciente das características é relatada como Síndrome de Domesticação (CLEMENT, 1992; CLEMENT et al., 2009) e pode ocorrer desde o início da formação das plântula, pois ocorre seleção para germinação rápida durante a produção de mudas (CLEMENT; 
DUDLEY, 1995) e também no semeio direto quando os agricultores realizam desbaste favorecendo as sementes que germinam primeiro. Em sementes de tucumã-do-amazonas, foi relatada dormência (NAZÁRIO; FERREIRA, 2010), e quando as condições de germinação no semeio direto não são suficientes para realizar a quebra da dormência de algumas sementes, ocorre seleção para germinação contra as sementes dormentes. Todos estes fundamentos explicam a superioridade da procedência de Maués comparada a Tarumã-Açu em relação à resposta à germinação.

A porcentagem de emergência de plântulas de tucumã-do-amazonas após 343 dias no viveiro de produção de mudas, para as sementes das procedências Tarumã-Açu e Maués (Figura 5), foi semelhante às porcentagens na pré-germinação (Figura 4), pois não houve significância da frequência de troca de água ou exposição a choques de temperaturas (Figura 5); somente se verificou significância para o efeito da procedência, pois a emergência de plântulas de
Maués foi significativamente superior à obtida com a utilização das sementes de Tarumã-Açu. A quase totalidade das sementes pré-germinadas transferidas para o substrato sobreviveu no viveiro e originou mudas. Após iniciado o processo de germinação, foram necessários, em média, 161 dias para se obter uma plântula com a primeira folha completa para procedência de Maués e para Tarumã, 192 dias. Para que haja sucesso na produção das culturas, as sementes devem germinar, e as plântulas emergir de maneira rápida e uniforme, de forma que a água, a luz e os nutrientes possam ser utilizados com o máximo de eficiência. As plântulas com desenvolvimento retardado e fraco, ao emergirem de maneira lenta e desuniforme, podem ser facilmente danificadas por pragas e doenças, causando prejuízos ao produtor de mudas (GUIMARÃES et al., 2008), além de gerar plantas que serão menos vigorosas e produtivas do que as oriundas de sementes que germinam e emergem rapidamente (MARTINS et al., 2009a

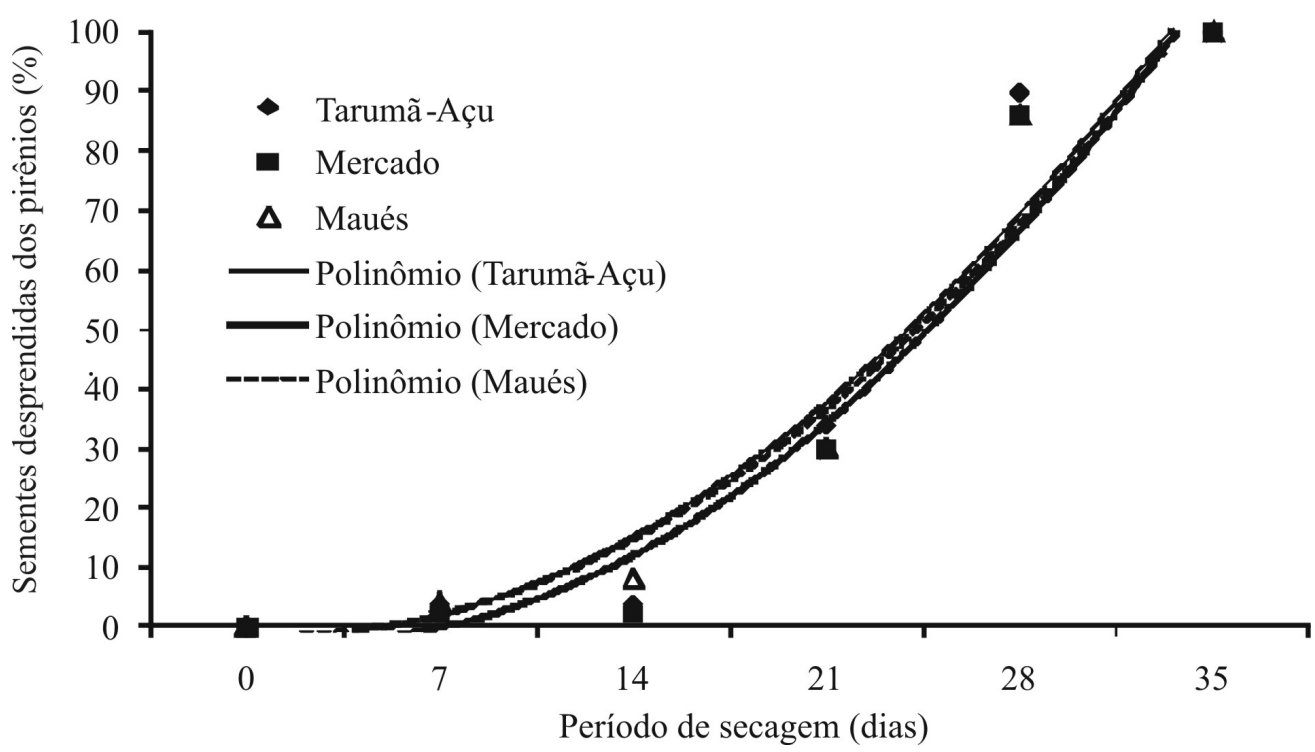

FIGURA 1 - Sementes desprendidas de pirênios de tucumã-do-amazonas do Tarumã-Açu (y=2,200$\left.9,236 \mathrm{x}+4,536 \mathrm{x}^{2}, \mathrm{R}^{2}=0,934\right)$, Mercado $\left(\mathrm{y}=6,000-13,214 \mathrm{x}+5,071 \mathrm{x}^{2}, \mathrm{R}^{2}=0,943\right)$ e Maués $\left(y=4,200-10,307 x+4,607 x^{2}, R 2=0,949\right)$. 


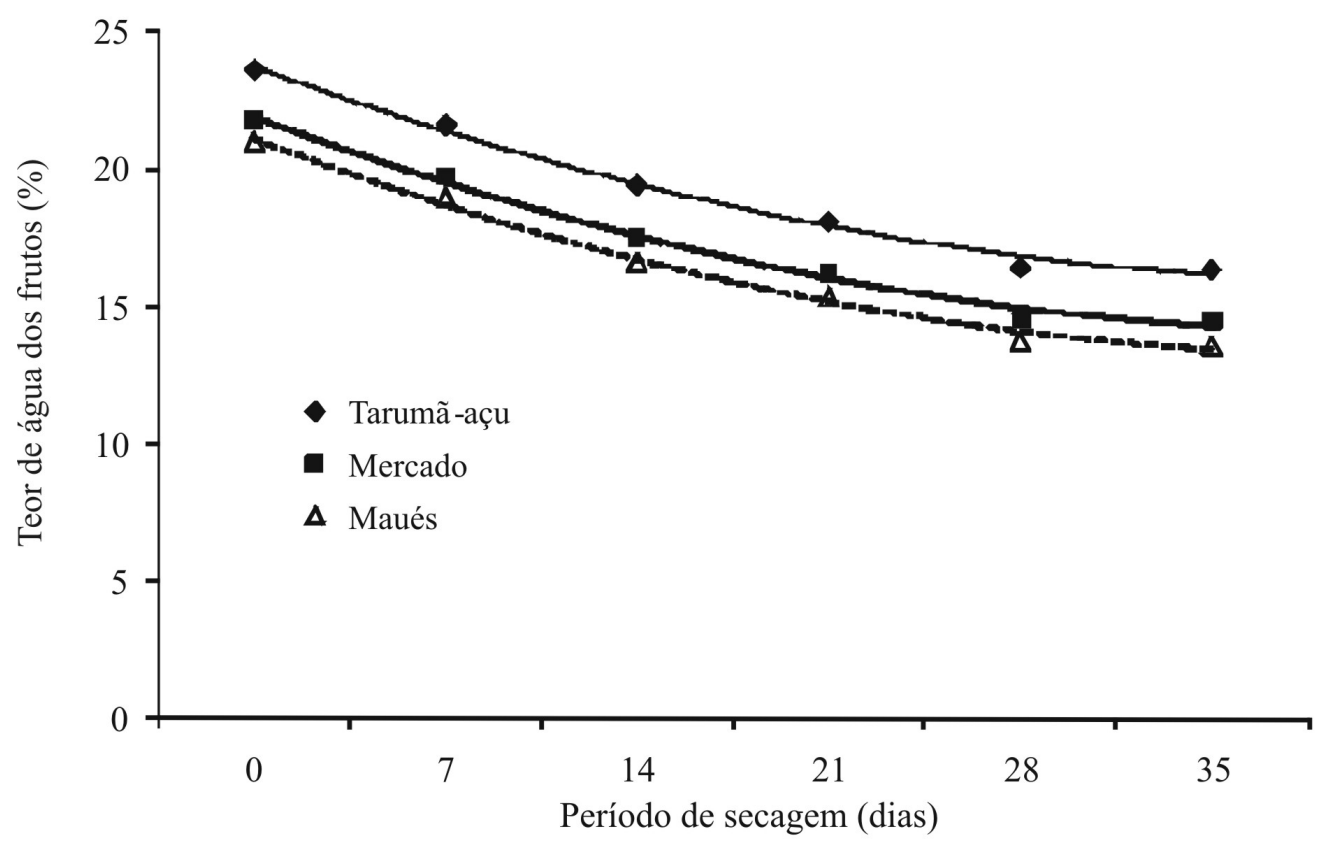

FIGURA 2 - Curvas de secagem de sementes de tucumã-do-amazonas das procedências Tarumã-Açu $\left(y=26,499-2,979 x+0,209 x^{2}, R^{2}=0,993\right)$, Mercado $\left(y=24,707-3,028 x+0,215 x^{2}, R^{2}=0,994\right)$ e Maués $\left(\mathrm{y}=23,948-3,074 \mathrm{x}+0,220 \mathrm{x}^{2}, \mathrm{R}^{2}=0,995\right)$.

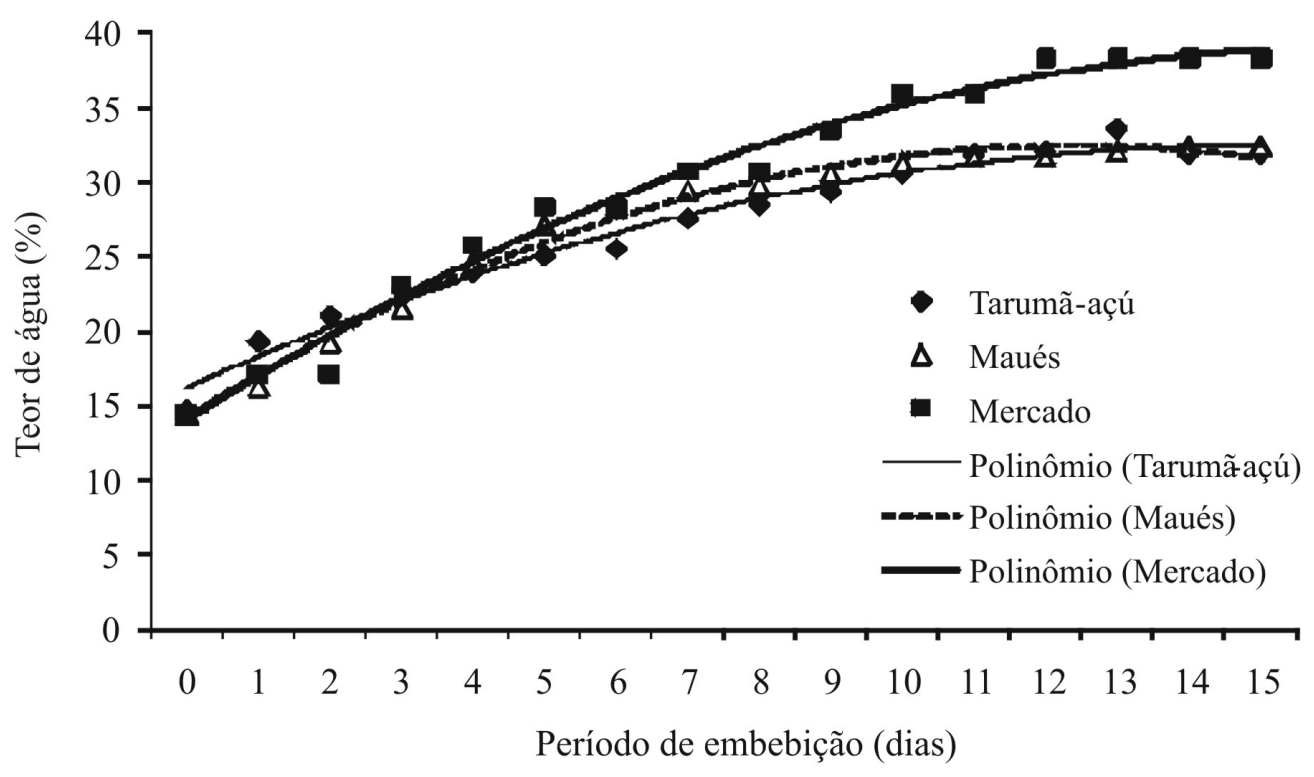

FIGURA 3 - Curvas de embebição das sementes de tucumã-do-amazonas das procedências Tarumã-Açu $\left(y=13,941+2,316 x-0,073 x^{2}, R^{2}=0,979\right)$, Mercado $\left(y=10,832-3,235 x+0,095 x^{2}, R^{2}=0,984\right)$ e Maués $\left(y=11,133+3,1857 x-0,119 x^{2}, R^{2}=0,990\right)$. 


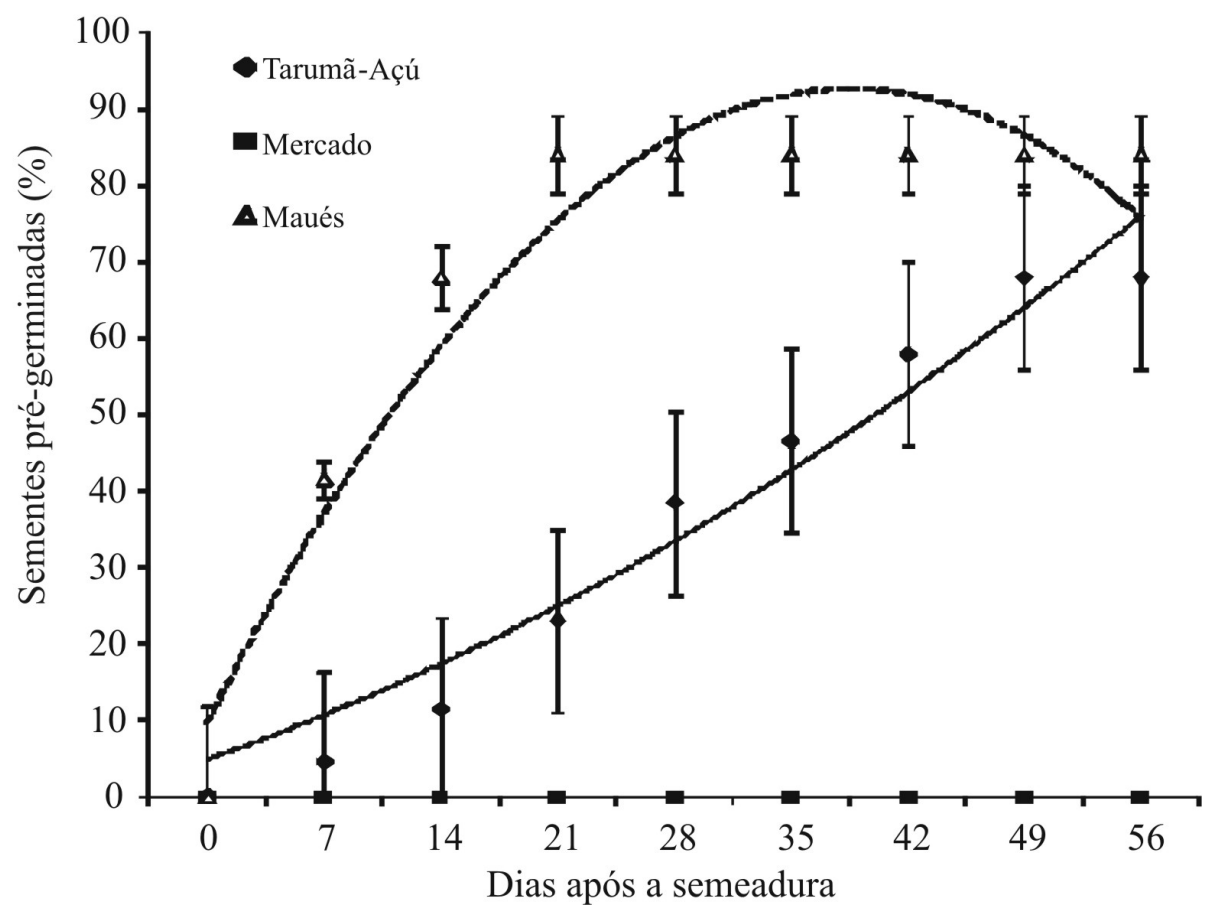

FIGURA 4 - Pré-germinação das sementes de tucumã-do-amazonas das procedências Tarumã-Açu $\left(y=0,441 x^{2}+4,477 x, R^{2}=0,9567\right)$, Maués $\left(y=-2,7289 x^{2}+35,547 x-23,155, R^{2}=0,9306\right)$ e Mercado.

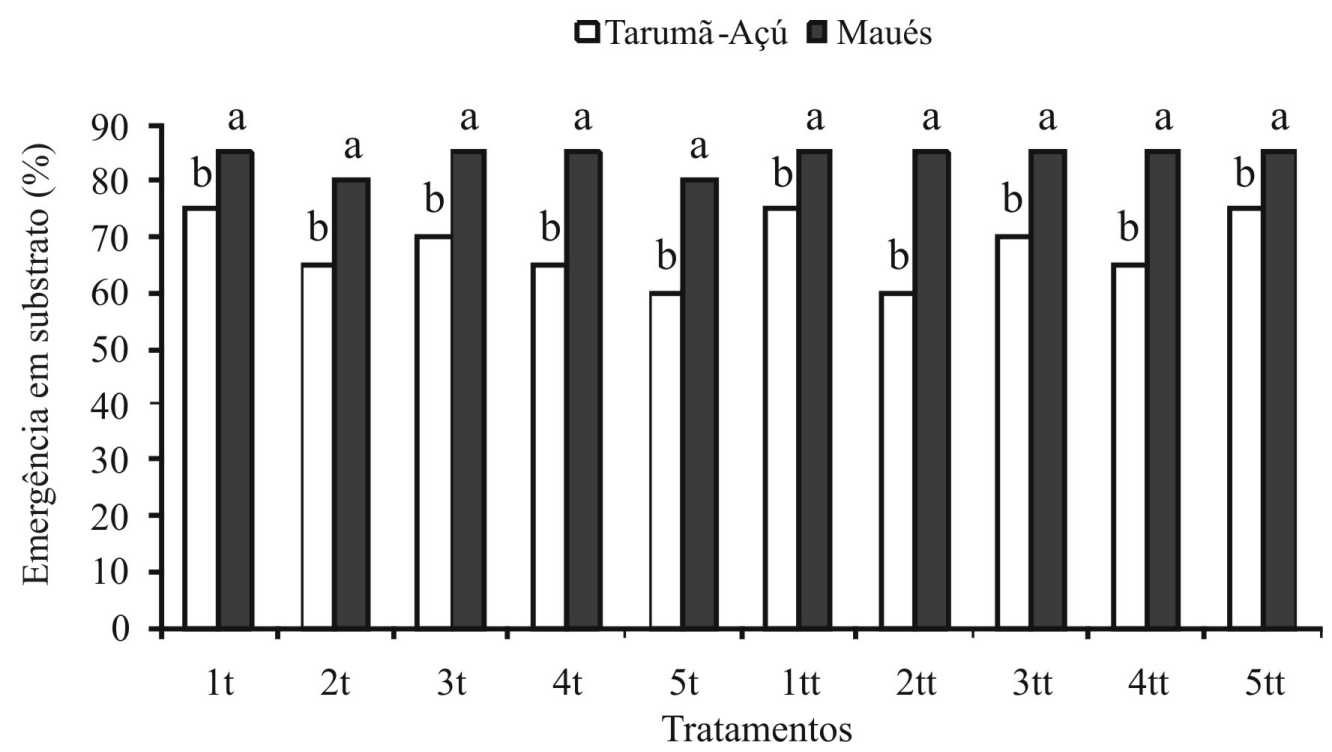

FIGURA 5 - Emergência de plântulas de tucumã-do-amazonas e produção de mudas após 343 dias no viveiro para as sementes das procedências Tarumã-Açu e Maués submetidas a uma (t) e duas (tt) trocas diárias de água e aos seguintes tratamentos: testemunha (1); imersão por 5 minutos em $\mathrm{H}_{2} \mathrm{O}$ a $50^{\circ} \mathrm{C}$ (2);imersão por 5 minuntos em $\mathrm{H}_{2} \mathrm{O}$ a $10^{\circ} \mathrm{C}$ (3); imersão por 5 minutos em $\mathrm{H}_{2} \mathrm{O}$ a $50^{\circ} \mathrm{C}$, seguida por $10^{\circ} \mathrm{C}$ por mais 5 minutos (4), e imersão por 5 minutos em $\mathrm{H}_{2} \mathrm{O}$ a $10^{\circ} \mathrm{C}$, seguida por $50^{\circ} \mathrm{C}$ por mais 5 minutos (5). Barras com diferentes letras minúsculas acima são diferentes, ao nível de $1 \%$ de probabilidade, pelo teste $\mathrm{F}$. 


\section{CONCLUSÕES}

1-A frequência de troca de água de embebição da semente e a exposição a choques de temperaturas não têm efeito sobre o desempenho germinativo das sementes em tucumã-do-amazonas.

2-A utilização de sementes geneticamente superiores de tucumã-do-amazonas, da população de Maués, possibilita maior germinação e produção de mudas em menor tempo.

\section{REFERÊNCIAS}

BRASIL. Ministério da Agricultura, Pecuária e Abastecimento. Secretaria de Defesa Agropecuária. Regras para análise de sementes. Brasília, 2009. $399 \mathrm{p}$.

COSTA, J.R.; VAN LEEUWEN, J.; COSTA, J.A. Tucumã-do-amazonas, Astrocaryum tucuma Martius. In: SHANLEY, P.; MEDINA, G. Frutíferas e plantas úteis na vida amazônica. Belém: CIFOR, Imazon. p.215-222, 2005.

CLEMENT, C.R. Domesticated palms. Principes, Miami, v.36, n.2, p.70-78, 1992.

CLEMENT, C.R.; BORÉM, A.; LOPES, M.T.G. Da domesticação ao melhoramento de plantas. In: BORÉM, A.; LOPES, M.T.G.; CLEMENT, C.R. (Org). Domesticação e melhoramento: espécies amazônicas. Viçosa: UFV, 2009. p. 11-38.

CLEMENT, C.R.; DUDLEY, N.S. Effect of Bottom Heat and Substrate on Seed Germination of Pejibaye (Bactris gasipaes) in Hawaii. Principes, Miami, , v.39, n.1, p.21-24, 1995.

FAO. Especies forestales productoras de frutas y otros alimentos. 3. Ejemplos de América Latina. Rome: FAO, 1987. 241p.
FERREIRA, S.A.N.; GENTIL, D.F.O. Extração, embebição e germinação de sementes de tucumã Astrocaryum aculeatum. Acta Amazonica, Manaus, v.36, n.2, p.141-146, 2006.

GENTIL, D.F.O.; FERREIRA, S.A.N. Morfologia da plântula em desenvolvimento de Astrocaryum aculeatum Meyer (Arecaceae). Acta Amazonica, Manaus, v.35, n.3, p.337-342, 2005.

GUIMARÃES, M.A.; DIAS, D.F.S; LOUREIRO, M.E. Hidratação de sementes. Revista Trópica Ciências Agrárias e Biológicas, Chapadinha, v.2, n.1, p. 31-39, 2008.

MARCOS FILHO, J. Fisiologia de sementes de plantas cultivadas. Piracicaba: FEALQ, 2005. 495p.

MARTINS, C.C.; BOVI, M.L.A.; SPIERING, S.H. Umedecimento do substrato na emergência e vigor de plântulas de pupunheira. Revista Brasileira de Fruticultura, Jaboticabal, v.31, n.1, p.224-230, 2009a.

MARTINS, C.C.; NAKAGAWA, J.; BOVI, M.L.A. Avaliação da qualidade fisiológica de sementes de açaí. Revista Brasileira de Fruticultura, Jaboticabal, v.31, n.1, p.231-235, 2009b.

MIRANDA, I.P.A.; RABELO, A.; BUENO, C.R.; BARBOSA, E.M.; RIBEIRO, M.N.S. Frutos de palmeiras da Amazônia. Manaus: MCT/INPA, 2001. 120p.

NAZÁRIO, P.; FERREIRA, S.A.N. Emergência de plântulas de Astrocaryum aculeatum G. May. em função da temperatura e do período de embebição das sementes. Acta Amazônica, Manaus, v.40, n.1, p. $165-170,2010$. 